\title{
Coronary Thrombus
}

\author{
${ }^{1}$ Department of Cardiology, STAR Hospitals, Hyderabad, \\ Telangana, India \\ ${ }^{2}$ Department of Cardiology, NIMS, Punjagutta, Hyderabad, \\ Telangana, India \\ Indian J Cardiovasc Dis Women-WINCARS 2017;2:e10-e20.
}

\section{Nemani Lalita ${ }^{2}$}

Address for correspondence Venkata Siva Krishna Kotapati, DM, STAR Hospitals, Banjara Hills, Hyderabad, Telangana 500034, India (e-mail: venkatasivakrishna.k@gmail.com).

tion or erosion because they consist of a crescentic mass of lipids either in close contact with the vessel lumen or separated from it by a discrete component of extracellular matrix.. ${ }^{10,11}$ Plaque disruption occurs most frequently where the fibrous cap is thinnest, most heavily infiltrated by lipid-filled macrophages (foam cells), and therefore weakest, and for eccentric plaques, this tends to be the shoulder region between the plaque and the adjacent vessel wall. ${ }^{12}$ However, the process is not purely mechanical, but an active process is involved in the pathophysiology. Atherectomy specimens from patients with ACSs reveal areas very rich in macrophages, ${ }^{13}$ and these cells are capable of degrading extracellular matrix by phagocytosis or secretion of proteolytic enzymes; thus, enzymes such as plasminogen activators and matrix metalloproteinases (MMPs: collagenases, gelatinases, and stromelysins) may weaken the fibrous cap and predispose it to rupture. The ensuing contact of exposed, disrupted, and highly thrombogenic subendothelial matrix and plaque with circulating platelets and white blood cells activates the coagulation cascade. The resultant platelet adhesion and aggregation lead to thrombus formation. Furthermore, released tissue factor from the arterial injury directly activates the extrinsic coagulation cascade and promotes fibrin formation. Activated platelets release powerful promoters of vasoconstriction and aggregation, including serotonin, adenosine diphosphate, thromboxane A2, oxygen-derived free radicals, endothelin, and plateletactivating factor. ${ }^{14}$ As the thrombus accumulates to form a critical obstacle, impaired flow dynamics alongside and distal to the thrombotic lesion develop, frequently accompanied by dynamic vasoconstriction and resultant clinical ischemic events. ${ }^{15}$

\section{Thrombosis-Substrate Dependent}

There is striking heterogeneity in the composition of human atherosclerotic plaques, even in the same individual, and the disruption of plaques exposes different vessel wall components to blood. Data on the thrombogenicity of disrupted atherosclerotic lesions are limited. The lipid core,
DOI https://doi.org/ 10.1055/s-0037-1607390.
Copyright Copyright @ 2017 Women in Cardiology and Related Sciences
License terms

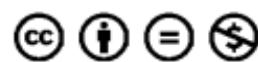


abundant in cholesterol ester, displayed by far the highest thrombogenicity. $^{16}$

\section{Thrombosis-Tissue Factor Dependent}

Tissue factor (TF), a small-molecular-weight glycoprotein, initiates the extrinsic clotting cascade and is believed to be a major regulator of coagulation, hemostasis, and thrombosis. TF forms a high-affinity complex with coagulation factors VII/VIIa; $\mathrm{TF} /$ VIla complex activates factors IX and $\mathrm{X}$, which in turn lead to thrombin generation. ${ }^{17} \mathrm{TF}$ antigen is normally present only in the arterial adventitia. Platelet deposition on lipid-rich atheromatous core was more than three times greater than on adventitia, with tunica media next, then foam-cell-rich matrix and collagen-rich matrix, and normal intima least thrombogenic. The lipid-rich core also exhibits the most intense TF staining, and this observation suggests that TF is an important determinant of the thrombogenicity of human atherosclerotic lesions after spontaneous or mechanical plaque disruption. Colocalization analysis of directional coronary atherectomy specimens from patients with unstable angina pointed to a strong relationship between TF and macrophages. ${ }^{18}$

\section{Thrombus in Acute Coronary Syndrome: Acute Thrombosis}

Disruption of a vulnerable or unstable plaque with a subsequent change in plaque geometry and thrombosis results in a complicated lesion. ${ }^{19,20}$ On occasion, the clinical consequence will be unstable angina or another ACS. ${ }^{19}$ However, it seems that such a thrombus more often causes no symptoms and, by self-organization, then contributes importantly to the progression of atherosclerosis.

The platelets sustain and amplify the coagulant response at the plaque site and release procoagulant platelet-derived microparticles. Various biochemical processes and interactions between activated platelets, red blood cells, fibrinogen, vasoconstrictors, atherosclerotic material, and the vessel wall all have a substantial impact on the fibrin network. These constituents account for the thrombus's level of activity, stability, or instability and for the overall "aggressiveness" of the thrombus as encountered during intervention. The presence and ratio of the aforementioned components lead to the formation of distinct thrombus types, each with unique rheolytic and mechanical properties. The two most prominent are the red and white thrombi. They can be detected by angioscopy, ${ }^{21}$ and their angiographic characteristics correlate with the histology of extracted thrombi. ${ }^{22}$ The red thrombus has a dense surface with a loose inner core. Transmission or scanning electron microscopy demonstrates loosely packed fibrin and many interspersed red blood cells. The white thrombus consists of a dense structure lacking loose inner spaces, yet it contains a high concentration of platelets with fibrin and only few red blood cells. ${ }^{23}$ Based on the histopathologic analysis of aspirated thrombotic content, erythrocyte-rich (red) thrombus is found in approximately $35 \%$ of patients, predominately in those presenting with low Thrombolysis In Myocardial Infarction (TIMI) flow. The platelet-rich (white) thrombus is identified in 65\% of cases, especially in the early hours of acute myocardial infarction. ${ }^{24}$
However, the fact is that in many patients the occlusive thrombus is a mixture of red and white clot, and the frequent resistance upon extraction attempts suggests that certain clots contain layers upon layers of one thrombus type interspersed with the other. ${ }^{25,26}$ From a clinical management viewpoint, coronary risk factors such as hypercholesterolemia, smoking, and male sex adversely influence plaque morphology in patients with ACSs and are associated with a higher frequency of thrombus.

\section{Detection of Thrombus-Containing Lesions}

Various imaging modalities are available for the diagnosis of intracoronary thrombus (-Figs. 1, 2). Angiography is the practical "gold standard" for the recognition of thrombus, demonstrating the classic findings of reduced contrast density, staining, haziness, irregular lesion contour, "filling defect," or a smooth convex meniscus at the site of a total thrombotic occlusion. Angiography is limited by poor sensitivity, although specificity approaches 100\% when multiple angiographic views are obtained and strict definitions are used. Nevertheless, when a thrombus is suspected but not apparent angiographically, the more sensitive techniques for its detection may be utilized, including angioscopy, ${ }^{27}$ intravascular ultrasound, ${ }^{28}$ and the recently introduced optical coherence tomography. ${ }^{29}$

\section{Thrombus Grading}

Grading systems are essential for adequate assessment of the thrombus burden and management decisions prior to and during interventions. The established and most commonly used thrombus grading classification was introduced by the TIMI Study Group. ${ }^{30}$ This method is based on the visual angiographic assessment of thrombus size, utilizing a score ranging from grades 0 through 5 .

An important modification to this scoring system was recently introduced by the thorax center investigators, who

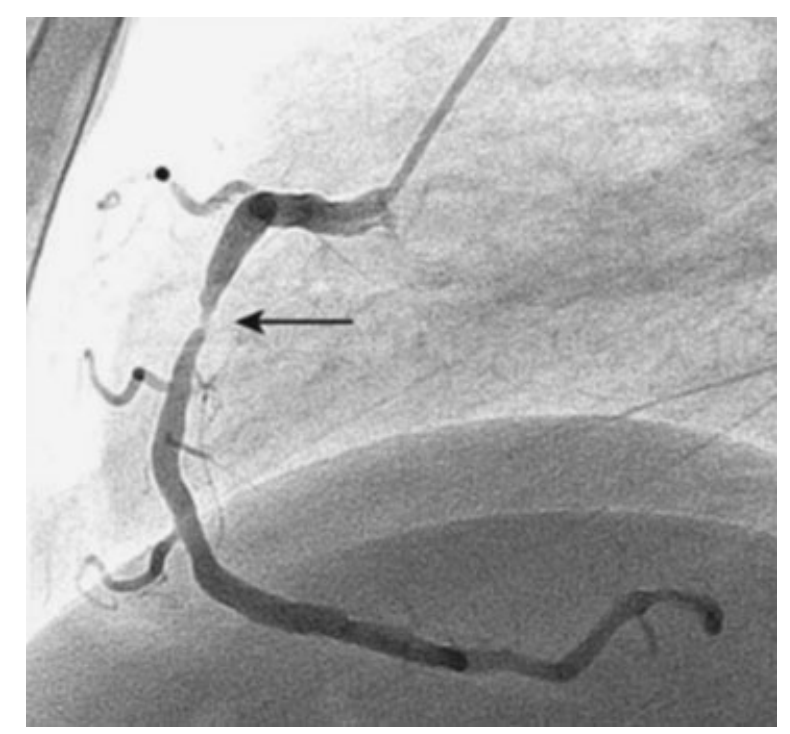

Fig. 1 Angiogram showing proximal RCA thrombotic lesion. RCA, right coronary artery. 




Fig. 2 OCT image of proximal RCA thrombotic lesion. OCT, optical coherence tomography; RCA, right coronary artery.

reclassified the highest grade (i.e., grade 5 ). When this grade is encountered, either a guidewire or a $1.5-\mathrm{mm}$ balloon (inflated or uninflated) is applied to recanalize the suspected thrombus. As soon as antegrade flow is restored, the exposed, apparently thrombotic content undergoes restratification into a small thrombus burden (grades 1-3) or a large thrombus burden (grade 4) and treatment ensues accordingly (-Tables 1-3).

Among the factors favoring thrombus formation, the relationship among hyperglycemia, increased white blood cell count, and findings of a high thrombus grade merits special clinical attention. ${ }^{31}$ These factors also adversely impact the achievement of proper ST-segment resolution during interventions and are associated with a worse PCI outcome. ${ }^{32} \mathrm{~A}$ plausible direct relationship between high thrombus content and large vessel size has been known for a long time; however, it has not been uniformly confirmed. ${ }^{31}$ Intriguingly, despite the convenience of the aforementioned classifications, most studies of $\mathrm{PCI}$ in ischemic coronary syndromes rarely measure, grade, or report the presence of any thrombotic burden. ${ }^{33}$

\section{Complications during Percutaneous Coronary Intervention}

Dislodgment of friable thrombotic material by balloon and stent deployment is an issue of significant concern, especially in heavy thrombus burden (grades 3-5) lesions. Embolization of fragmented thrombotic particles obstructs flow within distal arterial segments, side branches, and myocardial microvessels. Overall, distal embolization occurs in the range of 6 to $15 \%$ of standard PCI for all lesion types in ACSs and is associated with up to a sevenfold increase in the rate of periprocedural MI. In most instances, resultant severe ischemia, microinfarctions, inflammatory response, and contractile dysfunction reduce coronary reserve and cause deleterious effects on recovery and salvage. ${ }^{34}$ These complications are especially encountered among patients who undergo primary PCI for acute myocardial infarction (AMI). When compared with the revascularization of thrombus-free lesions, embolization also significantly increases the need for emergency bypass surgery as well as the procedure-related death rate. ${ }^{35}$ The considerably limited yield of standard PCI in thrombus-containing lesions is further elucidated by the phenomenon of "illusion of reperfusion." 36 Essentially, this term describes a marked discrepancy between primary PCI-gained TIMI 3 flow versus the disappointing,

Table 1 Thrombus grading scores

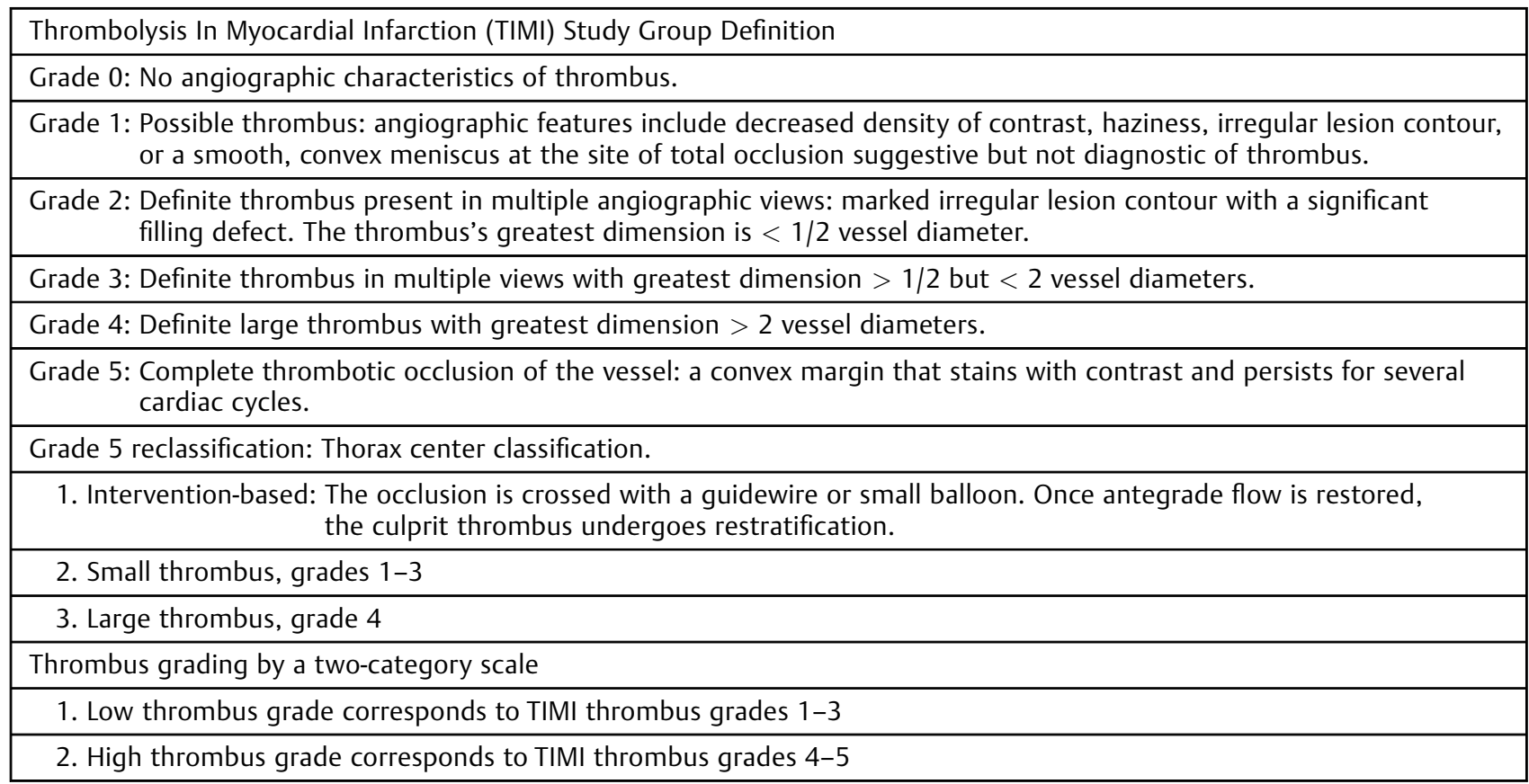

Abbreviation: TIMI, Thrombolysis In Myocardial Infarction. 
Table 2 Advantages and limitations of contemporary thrombus grading classifications

\begin{tabular}{|l|}
\hline Advantages \\
\hline 1. Convenient assessment during diagnostic angiography and interventions \\
\hline 2. Constitute logical grading scales that are readily available and globally applied \\
\hline 3. High inter- and intraobserver agreement \\
\hline 4. Correlate well with clinical outcomes \\
\hline 5. Reliable tools for comparison with previous angiograms \\
\hline Limitations \\
\hline 1. Based solely on visual assessment of the thrombus \\
\hline 2. Underestimation of thrombus presence and size in comparison with angioscopy and intracoronary ultrasound \\
\hline 3. Do not differentiate between types of thrombi \\
\hline 4. Inability to assess the thrombotic content of chronic total occlusions \\
\hline 5. Do not incorporate quantitation or qualification of the underlying plaque \\
\hline
\end{tabular}

Table 3 Factors favoring formation of a high-grade thrombus in atherosclerotic lesions

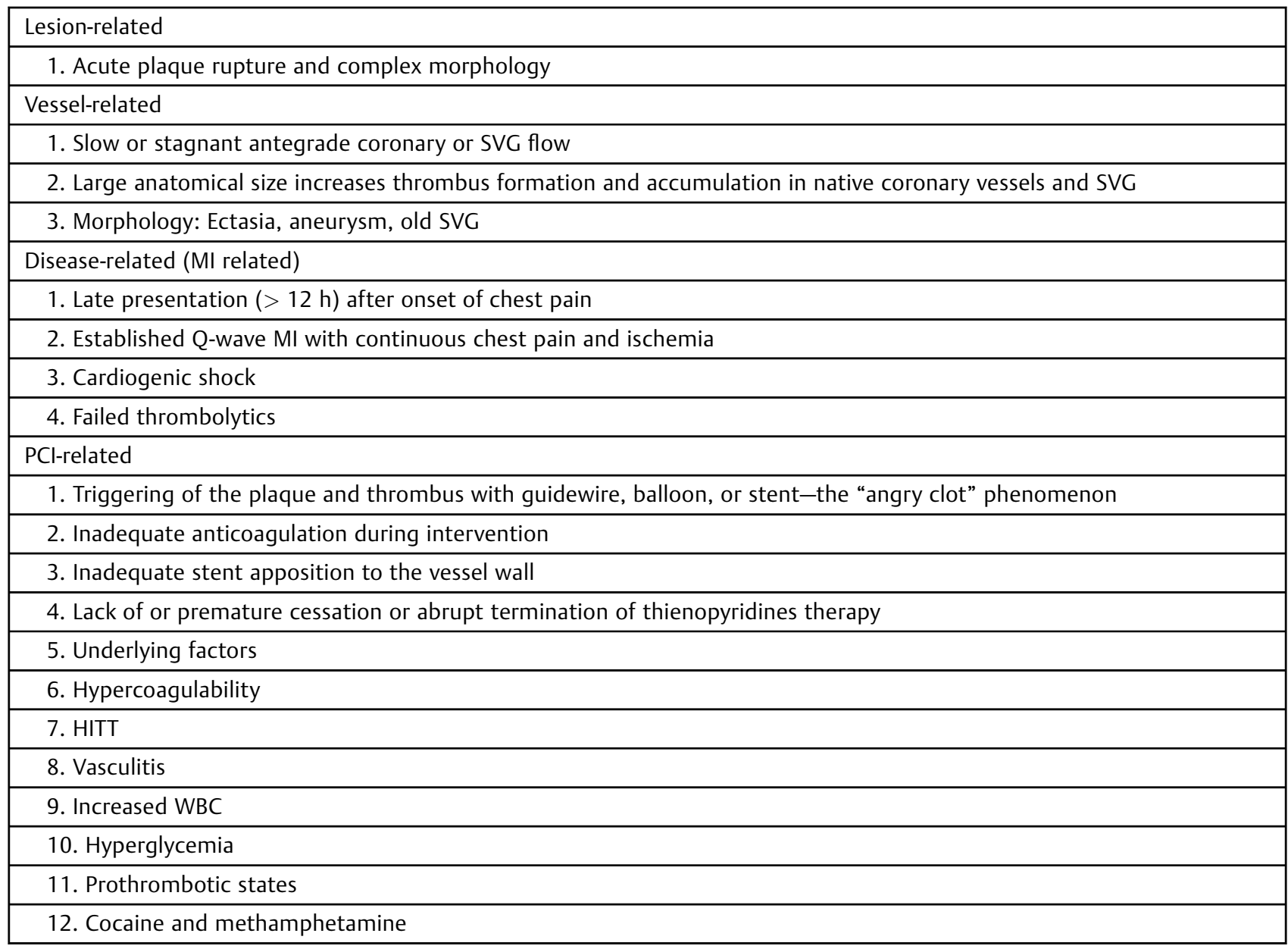

Abbreviatios: HITT, heparin-induced thrombocytopenia and thrombosis; MI, myocardial infarction; PCI, percutaneous coronary intervention; SVG, saphenous vein graft; WBC, white blood cells.

suboptimal degree of myocardial salvage. Notably, the desired grade 3 myocardial blush score is gained in only 28 to $35 \%$ of patients in whom the standard PCI induces a TIMI 3 epicardial flow. ${ }^{37}$ The main causes of this marked discrepancy include the prevalent intracoronary thrombus and related distal emboli- zation, microvessel obstruction, no reflow, and myocardial necrosis. Clearly, patients who develop procedure-related "no reflow" sustain larger-sized infarcts, significantly worse left ventricular (LV) function, and a greater risk of adverse cardiac events and death. ${ }^{38}$ Thus the deleterious impact of thrombus 
Table 4 Indications for a targeted thrombus strategy

\begin{tabular}{|l|}
\hline Pathology \\
\hline Atherosclerosis with associated thrombus \\
\hline Thrombotic embolus in a coronary artery or SVG \\
\hline $\begin{array}{l}\text { Intracoronary thrombus accumulation secondary to } \\
\text { hypercoagulability }\end{array}$ \\
\hline Clinical \\
\hline $\begin{array}{l}\text { Unstable and stable angina, STEMI, non-STEMI associated } \\
\text { with: }\end{array}$ \\
\hline Need to reduce thrombus burden in clot-laden lesions \\
\hline Need to reduce thrombus impairment to forward flow \\
\hline Need to reduce threat of thrombotic embolization \\
\hline Need to reduce risk of "no reflow" \\
\hline Targets \\
\hline $\begin{array}{l}\text { Native coronary arteries, old SVGs, chronic total } \\
\text { occlusions, stents }\end{array}$ \\
\hline
\end{tabular}

Abbreviations: ST-elevation myocardial infarction (STEMI); SVG, saphenous vein graft.

as a hazardous material that promotes adverse coronary events and suboptimal outcome should be anticipated and dealt with promptly before, during, and after PCI.

\section{Indications for a Targeted Thrombus Strategy}

In the absence of an apparent thrombus or when only a small thrombus (corresponding to grades 1-2) is detected, the recommended PCI strategy includes standard pharmacotherapy, balloon angioplasty, and stenting. ${ }^{39}$ Aspiration catheters can be useful as well in this situation. The management of a significant (grade 3) or heavy thrombotic burden (grades 4-5) is considerably more challenging. ${ }^{40}$ Targeted thrombus strategy is warranted in such situations, especially when the below mentioned pathologic, clinical featured demand. - Table 4.

\section{Pharmacotherapy}

The mainstay pharmacologic treatments for the management of thrombus-containing lesions include aspirin, heparin, glycoprotein IIb/IIIa platelet receptor antagonists, thienopyridines (clopidogrel, prasugrel, ticlopidine), and direct thrombin inhibitors. Interestingly, a beneficial decrease in the thrombotic burden can be gained with the mainstay agents even before the initiation of an intervention, with resultant improved $\mathrm{PCI}$ results and reduced risk of distal thrombotic embolization.

- Chronic aspirin therapy has been shown to decrease the thrombotic burden before stent deployment.

- Heparin reduces fibrin formation and abolishes platelet contractile forces. ${ }^{41}$

- Glycoprotein IIb/IIIa receptor antagonists dramatically reduce platelet aggregate size as well as to improve thrombolytic access to the platelet-rich clot's fibrin. ${ }^{42}$

However, these agents are less effective in an already formed, active, unstable thrombus, ${ }^{43}$ especially when it is a high-grade thrombus. For example, significant limitations of these useful pharmacologic therapies are quite apparent during the revascularization of old saphenous vein grafts (SVGs) with a large thrombotic content. ${ }^{44}$

\section{Approach to Mechanical Thrombus Removal}

Contemporary mechanical thrombus removal or dissolution devices can be categorized into four main types, according to their activation mode:

1. Manual aspiration catheters

2. Power-sourced thrombectomy

3. Ultrasound-induced sonication

4. Embolic protection

Technically, thrombus removal devices are user-friendly owing to a relatively small size and convenient rapid delivery. Their efficiency contributes to the reduction in procedurerelated radiation exposure. A different classification of these devices defines thrombus extraction modalities as either "simple" (i.e., aspiration-based) or "complex" (i.e., mechanically based). ${ }^{45}$ The clinical benefits of thrombectomy appeared to be influenced by the device type, with a trend toward survival benefit with manual aspiration catheters and worse outcomes with mechanical devices. Facing the large variability of thrombus content and size among patients with ACSs, well-trained operators can choose the device according to the angiographic morphologic features of the targeted thrombus burden, often achieving excellent results with any of these tools. The TAPAS (The Thrombus Aspiration during Percutaneous Coronary Intervention in Acute Myocardial Infarction Study) study investigators ${ }^{44}$ found that thrombus aspiration is applicable in a large majority of patients with ST-elevation myocardial infarction (STEMI), affording better reperfusion and clinical outcomes than PCI without a mechanical thrombus removal strategy. However, it is unclear whether these findings are attributed to an immediate reduction in thrombotic burden, facilitation of direct stenting, or a combination of the two (-Table 5 ).

\section{Thrombus Aspiration Catheters}

Manual thrombus aspiration of the infarct-related vessel has attracted intense interest as a useful method for the rapid reduction in thrombotic burden, prevention of thrombus embolization, preservation of microvascular integrity, and reduction in infarct size. ${ }^{46}$ Most aspiration-based catheters are available in 4- to $6 \mathrm{~F}$ sizes; they contain an extraction lumen and aspiration syringe. They are user-friendly because of their low crossing profile, hydrophilic coating, flexibility, and tapered distal tip ${ }^{47}$ (- Fig. 3).

Meta analysis of randomized studies on catheter thrombus aspiration shows a significant benefit of reducing mortality compared with $\mathrm{PCI}$ alone, $2.7 \%$ versus $4.4 \%(p=0.05)$, respectively. ${ }^{48}$ However, some investigators failed to find any advantage to the routine use of aspiration catheters in STEMI patients, observing that this approach does not increase myocardial salvage and, in fact, may increase final infarct size. ${ }^{49}$ In the TOTAL (Thrombectomy with PCI versus PCI Alone) trial, patients 
Table 5 Utility of thrombectomy devices

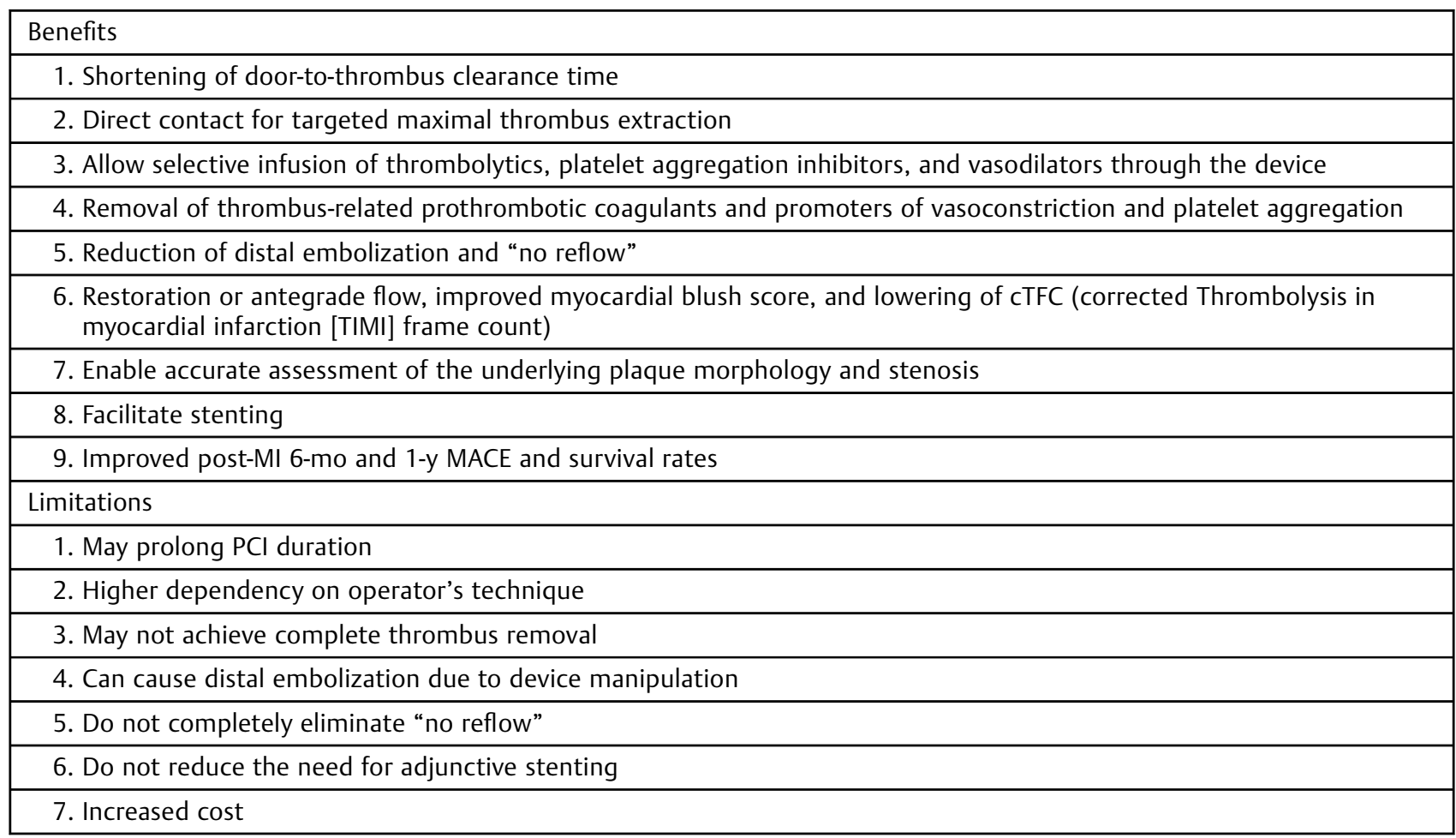

Abbreviations: CTFC, cCorrected TIMI Frame Count; MACE, major adverse cardiovascular events; TIMI, Thrombolysis In Myocardial Infarction; PCI percutaneous coronary intervention.

with STEMI who were undergoing primary $\mathrm{PCI}$, routine manual thrombectomy, as compared with PCI alone, showed no reduction in the risk of cardiovascular death, recurrent MI, cardiogenic shock, or the New York Heart Association (NYHA) class IV heart failure within 180 days but was associated with an increased rate of stroke within 30 days. ${ }^{50}$ Among the limitations of aspiration catheters are the difficult delivery along tortuous vessels and reduced ability to aspirate at the distal coronary segments; there is also the risk of dissection/perforation in cases in which the guidewire is not located within the true lumen. The low, negative aspiration pressure and the small evacuation holes also limit the yield of these catheters in the presence of a large thrombotic volume. Commonly, the application of aspiration catheters results in inadequate clot extraction, leaving at least 30 to $50 \%$ residual thrombus volume. ${ }^{47}$ The considerable risk of catheter-induced distal embolization, especially during a hurried maneuver, and the need to repeatedly pass across a large thrombus, should be taken into account in planning clot extraction. It is noteworthy that even the sequential use of thrombus aspiration catheters and distal protection filters is associated with insufficient thrombus removal. ${ }^{47-49}$

\section{Power-Sourced Thrombectomy Devices}

This group of mechanical tools includes the rheolytic thrombectomy, the excimer laser, and the X-Sizer (eV3, Plymouth, Minnesota, United States). The question of whether powerbased mechanical thrombectomy offers any advantage over aspiration catheters is relevant to practical management, although there are no prospective studies with direct comparisons between these two modalities. Overall, there is a strong
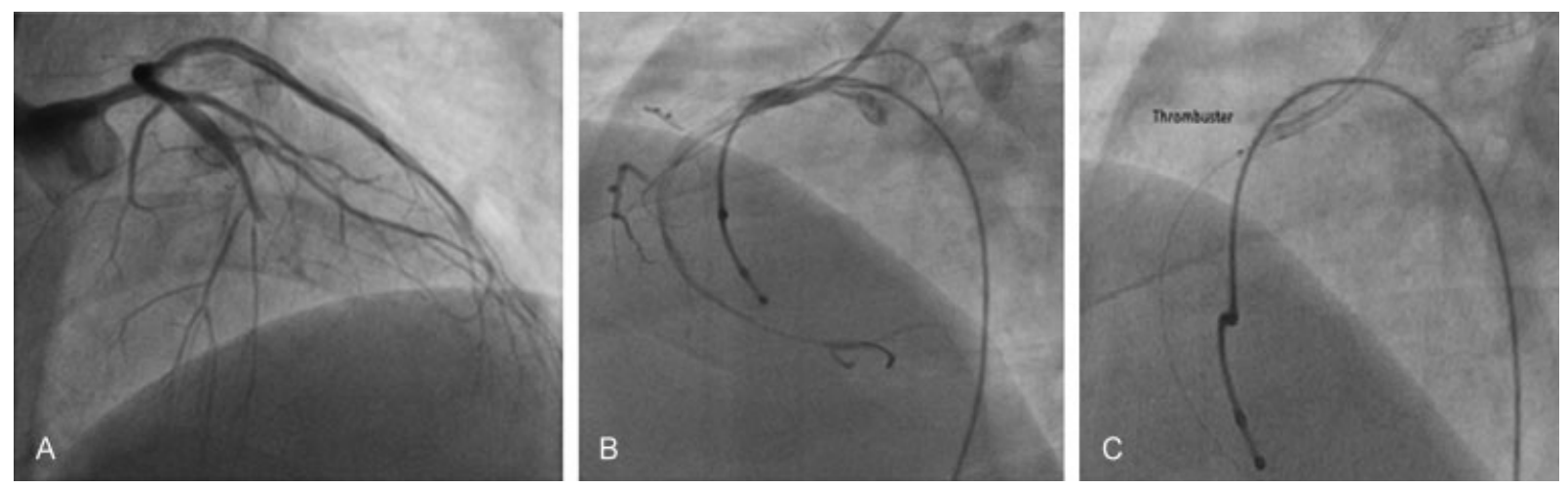

Fig. 3 Rheolytic thrombectomy system. Double vessel acute thrombotic occlusion in ACS patients. (A) Mid-LAD thrombotic occlusion with establishment of flow after wiring. (C) Usage of thrombuster. ACS, acute coronary syndromes; LAD, left anterior descending artery. 


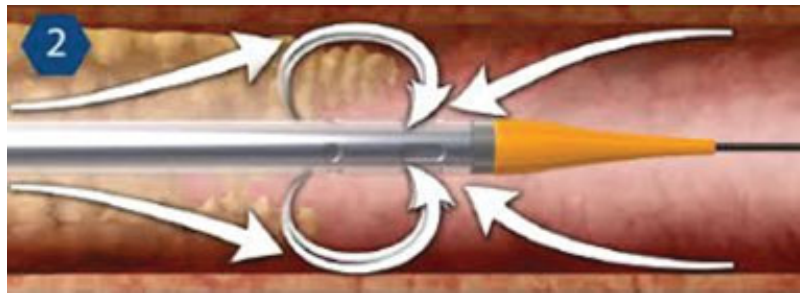

Fig. 4 Angiojet rheolytic thrombectomy.

clinical impression that the larger the target thrombus, the higher the extracting yield of a power-based mechanical thrombectomy device. ${ }^{46,51}$

The X-Sizer thrombectomy system is used mainly in Europe (-Fig. 4). It consists of a helical cutter enclosed in a protective housing attached to a dual-bore catheter shaft containing a guidewire and vacuum/extraction lumens. Activation of the handheld controller simultaneously rotates the helical cutter at 2,100 rpm (revolutions per minute), which entraps and macerates soft atherosclerotic plaque and thrombus and channels to a vacuum collection bottle. The device operates cutters $1.5,2$, and $2.3 \mathrm{~mm}$ in diameter and is compatible with 0.014 -in guidewires. ${ }^{52,53}$ The large, prospective X-Sizer in Acute Myocardial Infarction Patients for Negligible Embolization (X-AMINE) multicenter study that followed demonstrated a success rate for the device of $87 \%$ and adequate thrombus removal in $95 \%$ of the lesions. ${ }^{54}$

The Angiojet rheolytic thrombectomy system (Angiojet, Possis/Medrad, Minneapolis, Minnesota, United States) is a Food and Drug Administration (FDA)-approved device for thrombus-containing lesions encountered in coronary and peripheral interventions. The principle of activation is based on the creation of saline jets inside the catheter that travel backward at high speed to create a negative pressure zone (Venturi effect). Side windows along the catheter tip optimize fluid flow, drawing thrombus into the catheter for fragmentation and removal (-Figs. 4, 5).

In the FAST (Florence Appraisal Study of rheolytic Thrombectomy) study, Angiojet was used in 116 AMI patients with extensive thrombus loads, leading to significant improvements in perfusion, as compared with a control group with similar thrombus loads who received standard PCI. ${ }^{55}$ The JetStent trial exclusively focused on AMI patients with angiographically visible thrombus, using only slow, single-pass, antegrade thrombectomy and a narrower temporal definition of early ST-segment resolution ( $>50 \%$ within 30 minutes) ${ }^{56}$ It enrolled 501 STEMI patients with visible thrombus (grades $1-4$ ) or with a totally occluded infarct-related vessel (thrombus grade 5 with subsequent restratification). A significant difference in MACE rate was observed between the groups at 1 and 6 months: $3.1 \%$ AngioJet versus $6.9 \%$ direct stenting ( $p=0.05$ ), and $12 \%$ versus $21 \%(p=0.01)$, respectively. No difference was found between the two approaches regarding myocardial blush score and corrected TIMI frame count. Multivariable regression analysis showed that randomization to rheolytic thrombectomy was a predictor of ST-segment resolution (odds ratio [OR] 1.7, 95\% confidence interval $[\mathrm{CI}] 1.03-2.8, p<0.039$ ) and 6 months

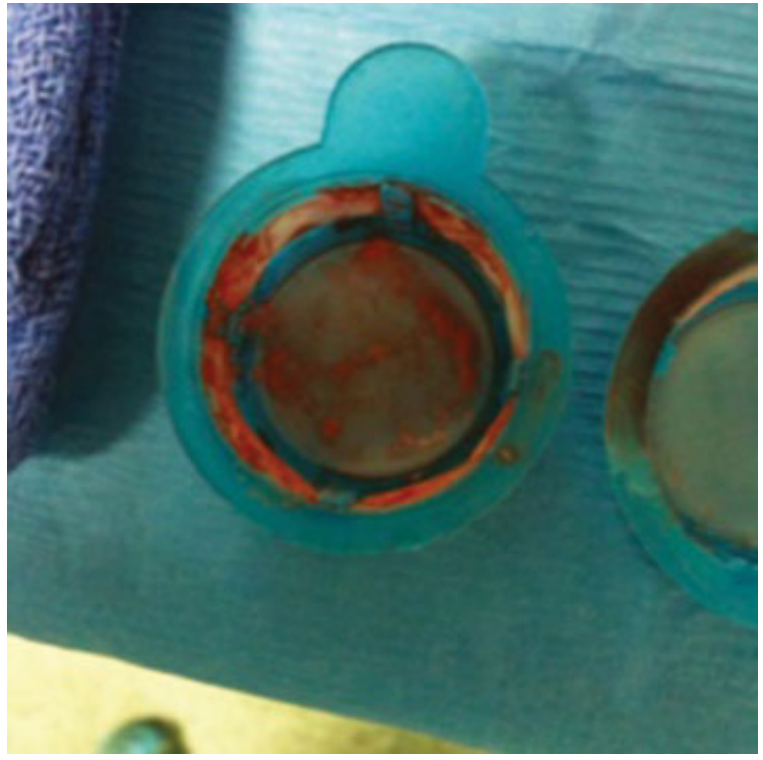

Fig. 5 Thrombus extracted from coronary

MACE rate. Despite the encouraging outcomes of the JetStent study, skepticism regarding the interpretation of results and the chance for wider use of this modality remains.

Lasers are mainly used for debulking lesions deemed unsuitable for standard PCI and can be applied for the revascularization of thrombus-containing lesions. ${ }^{57}$ The pulsed-wave ultraviolet-wavelength excimer laser (Spectranetics, Colorado Springs, Colorado, United States) has been successfully applied in patients with ACSs, including AMI. ${ }^{58}$ The excimer laser light interacts favorably with several components of the occluding thrombus. Laser-generated acoustic shock waves dissolve fibrin fibers and suppress platelet aggregation. ${ }^{59}$ The thrombus-dissolution capability of this laser was further examined by the Excimer laser angioplasty in acute myocardial infarction (CARMEL) multicenter study ${ }^{60}$

A baseline TIMI 0 flow of $1.2 \pm 1.1$ increased to $2.8 \pm 0.5$ with the laser energy and was followed by final TIMI flow of $3.0 \pm 0.2(p<0.001$ vs. baseline) with adjunctive stenting. Total MACE was relatively low at $13 \%$. Thus this study provided the first scientific, quantitative evidence of the considerable benefit of a dedicated mechanical thrombectomy device in thrombus-removal strategy and particularly in AMI.

Ultrasound-induced thrombus dissolution can be offered as adjunctive therapy aimed at increasing the efficacy of common thrombolytic therapies. ${ }^{61}$ Ultrasound-producing devices are defined by their different acoustic intensity and frequency, ranging from low $(20-400 \mathrm{KHz})$ to high $(0.5-3 \mathrm{KHz})$. The two main approaches to sonication therapy rely on an external device delivering transcutaneous therapeutic ultrasound energy $^{62}$ and on the invasive, intravessel catheter, which delivers sonication directly to the targeted thrombus.

\section{Stents with Thrombus Capturing Mechanisms}

During PCI, direct stenting of thrombus-containing lesions with either bare metal or drug-eluting stents is a common strategy. ${ }^{63}$ Conceptually, a dedicated thrombus-trapping stent could offer a targeted approach to the management 
of thrombus and reduction in embolization. The MGuard stent (Inspire-MD, Tel-Aviv, Israel) was developed for providing a unique stainless steel bare metal stent covered with an ultrathin, micrometer-level $(150 \times 180 \mu \mathrm{m})$, flexible mesh net fabricated by circular knitting. During stent deployment, the net stretches and slides over the expanding stent struts, creating custom-designed pores parallel to the vessel wall. Once deployed, the MGuard stent seals the thrombus and accompanying plaque and captures potential embolic debris between the fiber net and the arterial wall. ${ }^{64}$

\section{Power Thrombectomy}

This unique reperfusion strategy is aimed at the treatment of ischemic lesions and vessels laden with very heavy thrombotic burdens and accompanying slow antegrade flow. It combines power-sourced mechanical thrombectomy with selective injection of thrombolytic agents into the target vessels. The thrombolytic agents can be selectively administered during the intervention through a dedicated perfusion balloon such as the ClearPath (Unisys) device.

\section{Stent Thrombosis}

Early, late, and very late stent thrombosis is an ominous clinical development that has a significant impact on clinical outcome. ${ }^{65}$ Stent thrombosis is often multifactorial. ${ }^{66}$ One of the major causes is post-PCI residual thrombus, which then either gradually accumulates over time or rapidly aggregates to form a fully occlusive thrombus. Stent thrombosis can become manifest by serious complications such as nonfatal and fatal $\mathrm{AMI}^{67,68}$ and marked hemodynamic instability. Expedient thrombus management is key to a favorable outcome, especially for patients who present with STEMI. ${ }^{66}$ Primary PCI, including additional stenting with or without thrombectomy, is effective in restoring vessel patency, but reocclusion and restenosis are frequent. ${ }^{69}$ The often raised practical question as to which device is best for the management of stent thrombosis can be addressed according to the amount of occlusive thrombus and associated clinical findings. ${ }^{70,71}$ While a small to medium thrombus load in a stable patient can be managed with combination therapy of pharmacological agents and an aspiration catheter, a large burden, especially in the presence of hemodynamic instability and ongoing ischemia, calls for enhanced removal by a power-based mechanical thrombectomy device. Nevertheless, even successful PCI for stent thrombosis is associated with a larger infarct and poorer outcome than in patients with de novo STEMI.

\section{Multivessel Coronary Thrombosis}

This is an uncommon occurrence that poses a considerable management challenge. Patients with simultaneous multivessel thrombosis frequently present with ACS, mostly with either STEMI or non-STEMI, accompanied by severe hemodynamic compromise. The pathophysiologic process that accounts for this situation begins when plaque ruptures, and resultant acute thrombosis of a single artery leads to the development of cardiogenic shock. This, in turn, further decreases coronary perfusion pressure; consequently, multivessel thrombus is formed on other preexisting lesions as well. ${ }^{72}$ Another mechanism of multivessel coronary thrombosis involves thrombotic embolization and the occlusion of multiple coronary vessels from a left chamber cardiac tumor. ${ }^{73}$ The optimal treatment approach to multivessel coronary thrombosis is unknown, varying considerably from PCI to urgent coronary artery bypass grafting (CABG). In instances in which the most critical culprit lesion can be identified with certainty, selective treatment with aspiration catheter, aggressive pharmacotherapy, and subsequent stenting can be beneficial. However, in a case of PCI failure or in patients with continuous global ischemia due to thrombus-laden lesions in the other coronary arteries (especially with accompanying hemodynamic deterioration), urgent $C A B G$ is the preferred management option.

Table 6 Steps to follow in SVG sculpturing

\begin{tabular}{|l|}
\hline 1. Engage the SVG with a supporting guiding catheter and carefully advance a penetrating guidewire onto the CTO \\
\hline 2. Enhance guidewire penetration with a support catheter \\
\hline $\begin{array}{l}\text { 3. Once the CTO has been crossed, allow the guidewire to reach the distal graft or enter the native vessel beyond the } \\
\text { anastomosis; exchange with a maximal support guidewire }\end{array}$ \\
\hline 4. Apply a mechanical thrombectomy device along the graft in a slow antegrade and retrograde fashion \\
\hline $\begin{array}{l}\text { 5. When restored antegrade flow is angiographically apparent, assess residual thrombus burden and the exposed } \\
\text { underlying lesions }\end{array}$ \\
\hline $\begin{array}{l}\text { 6. In the case of significant residual thrombus, selectively inject into the graft 10- to 20-mg and allow } 10 \text { to } 15 \text { min for } \\
\text { interaction with the thrombus }\end{array}$ \\
\hline 7. Repeat thrombectomy for further reduction of the clot burden \\
\hline 8. Dilate/stent the underlying graft stenoses as indicated \\
\hline 9. A protection device can be added at the discretion of the operator \\
\hline $\begin{array}{l}\text { 10. Adjunctive pharmacotherapy can be added at the discretion of the operator; agents may include aspirin, heparin, } \\
\text { GP IIb/Illa platelet receptor blocker, direct thrombin inhibitor, thienopyridines, nitroglycerin, adenosine, or thrombolytic }\end{array}$ \\
\hline
\end{tabular}

Abbreviations: CTO, chronic total occlusion; GP, glycoprotein; SVG saphenous vein graft; tPA, tissue plasminogen activator. 


\section{Bypass Grafts}

Myocardial ischemia occurring early after CABG is typically caused by graft thrombosis resulting from surgery-related mechanical issues, whereas late ischemic events are caused by progression of soft, friable atheromatous plaques in the grafts. ${ }^{74,75}$ Collagen-rich (firm) or collagen-poor (soft) thrombus superimposition, an integral component of this process, is found in as many as $80 \%$ of old bypass grafts. ${ }^{76}$ The thrombotic content is often much greater in vein grafts than in native arteries because of the greater caliber of vein grafts and the lack of side branches, conditions that promote blood stagnation and coagulation. SVG sculpturing can be used to facilitate revascularization of totally occluded grafts through maximal removal of their thrombus content and subsequent stenting (-Table $\mathbf{6})$.

\section{Conclusion}

Thrombus plays a major role in the pathophysiology of ACSs. Understanding the structural components of the thrombus and proper assessment of its burden are essential steps for tailoring appropriate strategies for revascularization. Developing precise algorithms for PCI management of thrombus-containing lesions is a difficult task because of the complex characteristics of coronary thrombus, the presence of underlying associated atherosclerotic plaque, and the anatomic characteristics of the host vessels. Enhanced capabilities of thrombus-defining diagnostic tools, development of newly dedicated pharmacotherapy, increased accuracy of thrombus classifications, and further availability of specific technologies are warranted. This prospect will undoubtedly lead to a significant improvement in the outcomes of interventions for ACSs.

\section{Conflict of Interest}

None.

\section{References}

1 Venkitachalam L, Kip KE, Selzer F, et al; Investigators of NHLBISponsored 1985-1986 PTCA and 1997-2006 Dynamic Registries. Twenty-year evolution of percutaneous coronary intervention and its impact on clinical outcomes: a report from the National Heart, Lung, and Blood Institute-sponsored, multicenter 19851986 PTCA and 1997-2006 Dynamic Registries. Circ Cardiovasc Interv 2009;2(01):6-13

2 Sianos G, Papafaklis MI, Daemen J, et al. Angiographic stent thrombosis after routine use of drug-eluting stents in ST-segment elevation myocardial infarction: the importance of thrombus burden. J Am Coll Cardiol 2007;50(07):573-583

3 Goto K, Lansky AJ, Nikolsky E, et al. Prognostic significance of coronary thrombus in patients undergoing percutaneous coronary intervention for acute coronary syndromes: a subanalysis of the ACUITY (Acute Catheterization and Urgent Intervention Triage strategY) trial. JACC Cardiovasc Interv 2011;4(07):769-777

4 Singh M, Berger PB, Ting HH, et al. Influence of coronary thrombus on outcome of percutaneous coronary angioplasty in the current era (the Mayo Clinic experience). Am J Cardiol 2001;88(10):1091-1096

5 White CJ, Ramee SR, Collins TJ, et al. Coronary thrombi increase PTCA risk. Angioscopy as a clinical tool. Circulation 1996;93(02):253-258

6 Fokkema ML, Vlaar PJ, Svilaas T, et al. Incidence and clinical consequences of distal embolization on the coronary angiogram after percutaneous coronary intervention for ST-elevation myocardial infarction. Eur Heart J 2009;30(08):908-915

7 Napodano M, Dariol G, Al Mamary AH, et al. Thrombus burden and myocardial damage during primary percutaneous coronary intervention. Am J Cardiol 2014;113(09):1449-1456

8 Freeman MR, Williams AE, Chisholm RJ, Armstrong PW. Intracoronary thrombus and complex morphology in unstable angina. Relation to timing of angiography and in-hospital cardiac events. Circulation 1989;80(01):17-23

9 Virmani R, Burke AP, Farb A, Kolodgie FD. Pathology of the unstable plaque. Prog Cardiovasc Dis 2002;44(05):349-356

10 Richardson PD, Davies MJ, Born GV. Influence of plaque configuration and stress distribution on fissuring of coronary atherosclerotic plaques. Lancet 1989;2(8669):941-944

11 Falk E, Shah PK, Fuster V. Coronary plaque disruption. Circulation 1995;92(03):657-671

12 Falk E. Plaque rupture with severe pre-existing stenosis precipitating coronary thrombosis. Characteristics of coronary atherosclerotic plaques underlying fatal occlusive thrombi. Br Heart J 1983;50(02):127-134

13 Moreno PR, Falk E, Palacios IF, Newell JB, Fuster V, Fallon JT. Macrophage infiltration in acute coronary syndromes. Implications for plaque rupture. Circulation 1994;90(02):775-778

14 Sami S, Willerson JT. Contemporary treatment of unstable angina and non-ST-segment-elevation myocardial infarction (part 1). Tex Heart Inst J 2010;37(02):141-148

15 Schwartz SM, Galis ZS, Rosenfeld ME, Falk E. Plaque rupture in humans and mice. Arterioscler Thromb Vasc Biol 2007;27(04): 705-713

16 Fernández-Ortiz A, Badimon JJ, Falk E, et al. Characterization of the relative thrombogenicity of atherosclerotic plaque components: implications for consequences of plaque rupture. J Am Coll Cardiol 1994;23(07):1562-1569

17 Banner DW, D'Arcy A, Chène $C$, et al. The crystal structure of the complex of blood coagulation factor VIIa with soluble tissue factor. Nature 1996;380(6569):41-46

18 Moreno PR, Bernardi VH, López-Cuéllar J, et al. Macrophages, smooth muscle cells, and tissue factor in unstable angina. Implications for cell-mediated thrombogenicity in acute coronary syndromes. Circulation 1996;94(12):3090-3097

19 Fuster V, Lewis A. Lewis A. Conner Memorial Lecture. Mechanisms leading to myocardial infarction: insights from studies of vascular biology. Circulation 1994;90(04):2126-2146

20 Stary HC, Chandler AB, Dinsmore RE, et al. A definition of advanced types of atherosclerotic lesions and a histological classification of atherosclerosis. A report from the Committee on Vascular Lesions of the Council on Arteriosclerosis, American Heart Association. Circulation 1995;92(05):1355-1374

21 Abela GS, Eisenberg JD, Mittleman MA, et al. Detecting and differentiating white from red coronary thrombus by angiography in angina pectoris and in acute myocardial infarction. Am J Cardiol 1999;83(01):94-97, A8

22 Beygui F, Collet JP, Nagaswami C, Weisel JW, Montalescot G. Images in cardiovascular medicine. Architecture of intracoronary thrombi in ST-elevation acute myocardial infarction: time makes the difference. Circulation 2006;113(02):e21-e23

23 Johnstone E, Friedl SE, Maheshwari A, Abela GS. Distinguishing characteristics of erythrocyte-rich and platelet-rich thrombus by intravascular ultrasound catheter system. J Thromb Thrombolysis 2007;24(03):233-239

24 Vlaar PJ, Svilaas T, Vogelzang M, et al. A comparison of 2 thrombus aspiration devices with histopathological analysis of retrieved material in patients presenting with ST-segment elevation myocardial infarction. JACC Cardiovasc Interv 2008;1(03):258-264

25 Topaz O. On the hostile massive thrombus and the means to eradicate it. Catheter Cardiovasc Interv 2005;65(02):280-281

26 Zhao HJ, Yan HB, Li D, et al. [Pathological analysis of aspirated materials from the culprit lesion in patients with acute 
myocardial infarction] [in Chinese]. Zhonghua Xin Xue Guan Bing Za Zhi 2009;37(09):785-789

27 Limbruno U, De Carlo M, Pistolesi S, et al. Distal embolization during primary angioplasty: histopathologic features and predictability. Am Heart J 2005;150(01):102-108

28 Teirstein PS, Schatz RA, Wong SC, Rocha-Singh KJ. Coronary stenting with angioscopic guidance. Am J Cardiol 1995;75(05):344-347

29 Bonello L, De Labriolle A, Lemesle G, et al. Intravascular ultrasound-guided percutaneous coronary interventions in contemporary practice. Arch Cardiovasc Dis 2009;102(02):143-151

30 Gibson CM, de Lemos JA, Murphy SA, et al; TIMI Study Group. Combination therapy with abciximab reduces angiographically evident thrombus in acute myocardial infarction: a TIMI 14 substudy. Circulation 2001;103(21):2550-2554

31 Niccoli G, Spaziani C, Marino M, et al. Effect of chronic Aspirin therapy on angiographic thrombotic burden in patients admitted for a first ST-elevation myocardial infarction. Am J Cardiol 2010; 105(05):587-591

32 Pinto DS, Kirtane AJ, Pride YB, et al; CLARITY-TIMI 28 Investigators. Association of blood glucose with angiographic and clinical outcomes among patients with ST-segment elevation myocardial infarction (from the CLARITY-TIMI-28 study). Am J Cardiol 2008; 101(03):303-307

33 Topaz O, Topaz A, Polkampally PR. Thrombectomy in acute myocardial infarction. Intervent Cardiol 2009;4:86-91

34 Heusch G, Kleinbongard P, Böse D, et al. Coronary microembolization: from bedside to bench and back to bedside. Circulation 2009;120(18):1822-1836

35 Ohtani T, Ueda Y, Shimizu M, et al. Association between cardiac troponin T elevation and angioscopic morphology of culprit lesion in patients with non-ST-segment elevation acute coronary syndrome. Am Heart J 2005;150(02):227-233

36 Lincoff AM, Topol EJ. Illusion of reperfusion. Does anyone achieve optimal reperfusion during acute myocardial infarction? Circulation 1993;88(03):1361-1374

37 Kaya MG, Arslan F, Abaci A, van der Heijden G, Timurkaynak T, Cengel A. Myocardial blush grade: a predictor for major adverse cardiac events after primary PTCA with stent implantation for acute myocardial infarction. Acta Cardiol 2007;62(05):445-451

38 Brosh D, Assali AR, Mager A, et al. Effect of no-reflow during primary percutaneous coronary intervention for acute myocardial infarction on six-month mortality. Am J Cardiol 2007;99(04):442-445

39 Kunadian V, Zorkun C, Williams SP, et al. Intracoronary pharmacotherapy in the management of coronary microvascular dysfunction. J Thromb Thrombolysis 2008;26(03):234-242

40 Eeckhout E, Kern MJ. The coronary no-reflow phenomenon: a review of mechanisms and therapies. Eur Heart J 2001;22(09):729-739

41 Carr ME Jr, Carr SL, Greilich PE. Heparin ablates force development during platelet mediated clot retraction. Thromb Haemost 1996; 75(04):674-678

42 Collet JP, Montalescot G, Lesty C, et al. Effects of Abciximab on the architecture of platelet-rich clots in patients with acute myocardial infarction undergoing primary coronary intervention. Circulation 2001;103(19):2328-2331

43 Silva JA. Percutaneous coronary intervention of thrombotic lesions: still challenging!. Catheter Cardiovasc Interv 2002;56(01):8-9

44 Kalyanasundaram A, Blankenship JC, Berger P, Herrmann H, McClure R, Moliterno D. Thrombus predicts ischemic complications during percutaneous coronary intervention in saphenous vein grafts: results from TARGET (do Tirofiban and ReoPro give similar efficacy trial?) Catheter Cardiovasc Interv 2007;69(05): 623-629

45 Mamas MA, Fraser D, Fath-Ordoubadi F. The role of thrombectomy and distal protection devices during percutaneous coronary interventions. Eurolntervention 2008;4(01):115-123

46 Matar F, Anderson D, Rossi P, et al. Benefits of rheolytic thrombectomy in patients with ST-elevation myocardial infarction and high thrombus burden: findings from the cardioquest interventional database. Cardiovasc Revasc Med 2008;9:113-114

47 Sardella G, Mancone M, Bucciarelli-Ducci C, et al. Thrombus aspiration during primary percutaneous coronary intervention improves myocardial reperfusion and reduces infarct size: the EXPIRA (thrombectomy with export catheter in infarct-related artery during primary percutaneous coronary intervention) prospective, randomized trial. J Am Coll Cardiol 2009;53(04):309-315

48 Bavry AA, Kumbhani DJ, Bhatt DL. Role of adjunctive thrombectomy and embolic protection devices in acute myocardial infarction: a comprehensive meta-analysis of randomized trials. Eur Heart J 2008;29(24):2989-3001

49 Kaltoft A, Bøttcher M, Nielsen SS, et al. Routine thrombectomy in percutaneous coronary intervention for acute ST-segment-elevation myocardial infarction: a randomized, controlled trial. Circulation 2006;114(01):40-47

50 Jolly SS, Cairns J, Yusuf S, et al. Design and rationale of the TOTAL trial: a randomized trial of routine aspiration ThrOmbecTomy with percutaneous coronary intervention $(\mathrm{PCI})$ versus PCI ALone in patients with ST-elevation myocardial infarction undergoing primary PCI. Am Heart J 2014;167(03):315-321.e1

51 Topaz O, Ebersole D, Das T, et al; CARMEL multicenter trial. Excimer laser angioplasty in acute myocardial infarction (the CARMEL multicenter trial). Am J Cardiol 2004;93(06):694-701

52 Beran G, Lang I, Schreiber W, et al. Intracoronary thrombectomy with the X-sizer catheter system improves epicardial flow and accelerates ST-segment resolution in patients with acute coronary syndrome: a prospective, randomized, controlled study. Circulation 2002;105(20):2355-2360

53 Napodano M, Pasquetto G, Saccà S, et al. Intracoronary thrombectomy improves myocardial reperfusion in patients undergoing direct angioplasty for acute myocardial infarction. J Am Coll Cardiol 2003;42(08):1395-1402

54 Lefèvre T, Garcia E, Reimers B, et al; X AMINE ST Investigators. Xsizer for thrombectomy in acute myocardial infarction improves STsegment resolution: results of the X-sizer in AMI for negligible embolization and optimal ST resolution (X AMINE ST) trial.J Am Coll Cardiol 2005;46(02):246-252

55 Margheri M, Falai M, Vittori G, et al. Safety and efficacy of the AngioJet in patients with acute myocardial infarction: results from the Florence Appraisal Study of Rheolytic Thrombectomy (FAST). J Invasive Cardiol 2006;18(10):481-486

56 Migliorini A, Stabile A, Rodriguez AE, et al; JETSTENT Trial Investigators. Comparison of AngioJet rheolytic thrombectomy before direct infarct artery stenting with direct stenting alone in patients with acute myocardial infarction. The JETSTENT trial. J Am Coll Cardiol 2010;56(16):1298-1306

57 Topaz O. Laser. In: Topol EJ (ed). Textbook of Interventional Cardiology. 4th ed. Philadelphia, PA: Saunders; 2003:675-703

58 Topaz O, Bernardo NL, Shah R, et al. Effectiveness of excimer laser coronary angioplasty in acute myocardial infarction or in unstable angina pectoris. Am J Cardiol 2001;87(07):849-855

59 Topaz O, Minisi AJ, Morris C, Mohanty PK, Carr Jr. Photoacoustic fibrinolysis: pulsed wave mid infrared laser-clot interaction. J Thromb Thrombolysis 1996;3(03):209-214

60 Topaz O, Minisi AJ, Bernardo NL, et al. Alterations of platelet aggregation kinetics with ultraviolet laser emission: the "stunned platelet" phenomenon. Thromb Haemost 2001;86(04):1087-1093

61 Xuedong Shen, Nair C, Holmberg M, Mooss A, Arouni A, Esterbrooks D. Therapeutic ultrasound-enhanced thrombolysis in patients with acute myocardial infarction. Angiology 2010;61(03):253-258

62 Cohen MG, Tuero E, Bluguermann J, et al. Transcutaneous ultrasound-facilitated coronary thrombolysis during acute myocardial infarction. Am J Cardiol 2003;92(04):454-457

63 Timurkaynak T, Ozdemir M, Cengel A, et al. Direct stenting in angiographically apparent thrombus-containing lesions. J Invasive Cardiol 2001;13(11):742-747 
64 Vaknin-Assa H, Assali A, Kornowski R. Preliminary experiences using the MGuard stent platform in saphenous vein graft lesions. Catheter Cardiovasc Interv 2009;74(07):1055-1057

65 Serruys PW, Onuma Y, Garg S, et al. 5-year clinical outcomes of the ARTS 2 of the sirolimus-eluting stent in the treatment of patients with multivessel de novo coronary artery lesions. J Am Coll Cardiol 2010;55(11):1093-1101

66 Costa JR Jr, Sousa A, Moreira AC, et al. Incidence and predictors of very late ( $>$ or $=4$ years) major cardiac adverse events in the DESIRE (Drug-Eluting Stents in the Real World)-Late registry. JACC Cardiovasc Interv 2010;3(01):12-18

67 Alexopoulos D, Xanthopoulou I, Davlouros P, et al. Mechanisms of nonfatal acute myocardial infarction late after stent implantation: the relative impact of disease progression, stent restenosis, and stent thrombosis. Am Heart J 2010;159(03):439-445

68 Garg S, Serruys P. Benefits of and safety concerns associated with drug-eluting coronary stents. Expert Rev Cardiovasc Ther 2010;8 (03):449-470

69 Ergelen M, Gorgulu S, Uyarel H, et al. The outcome of primary percutaneous coronary intervention for stent thrombosis causing ST-elevation myocardial infarction. Am Heart J 2010;159(04): 672-676
70 Parodi G, Memisha G, Bellandi B, et al. Effectiveness of primary percutaneous coronary interventions for stent thrombosis. Am J Cardiol 2009;103(07):913-916

71 Topaz O. Late stent thrombosis: is Angiojet rheolytic thrombectomy the preferred revascularization technique? Catheter Cardiovasc Interv 2003;58:18-19

72 Turgeman Y, Suleiman K, Atar S. Multivessel acute coronary thrombosis and occlusion-an unusual cause of cardiogenic shock. J Invasive Cardiol 2007;19(09):E278-E280

73 Konagai N, Cho M, Nakamura K, Shigematsu H. Left atrial myxoma as a cause of acute myocardial infarction. Tex Heart Inst J 2010;37 (01):125-126

74 Parang P, Arora R. Coronary vein graft disease: pathogenesis and prevention. Can J Cardiol 2009;25(02):e57-e62

75 Yong A, Groenestein P, Brieger D, Lowe H, Kritharides L. Late thrombotic occlusion of a left internal mammary artery graft causing ST-elevation myocardial infarction. Int J Cardiol 2010; 142(03):e42-e44

76 Hata M, Takayama T, Sezai A, Yoshitake I, Hirayama A, Minami K. Efficacy of aggressive lipid controlling therapy for preventing saphenous vein graft disease. Ann Thorac Surg 2009;88(05):1440-1444 